\title{
Research on Improving the Innovative Ability of Environmental Engineering Graduate Students
}

\author{
Zhang Shuqin \\ College of Environment Science and Technology \\ Wuhan University of Science and Technology \\ Wuhan Hubei \\ zhangwuxia@163.com
}

\author{
Liu Hai \\ College of Environment Science and Technology \\ Wuhan University of Science and Technology \\ Wuhan Hubei
}

\author{
Deng Zhiqun \\ College of Environment Science and Technology \\ Wuhan University of Science and Technology \\ Wuhan Hubei
}

\begin{abstract}
In order to improve the graduate professional technology level and increase the employment competitive power, this paper explores a set of suitable education training mode and the corresponding management measures for the master of graduate students. According to the usual experience summary of master of environmental engineering, this paper applies the way that is to improve the students' professional and engineering application of target setting, optimization of experimental system from the curriculum with professional degree in environmental engineering's graduate training. Through reforming the training system, optimizing the training methods and improving the teaching methods, the research ability of graduate students and the cultivation of practical innovation ability of graduate students were promoted.
\end{abstract}

Keywords-Innovative ability; Environmental engineering; Professional degree;Master;Employment competitive power

\section{INTRODUCTION}

With the deepening development of environmental protection industry in our country, environmental engineering talents cultivation has got more and more attention from society and universities[1-2]. However, our country environmental engineering graduate's employment rate is lower than the same period the national average from the perspective of the employment of current [3-4].

To response to the characteristics of diversity, complexity, globalization of environmental problems in our country, we build a comprehensive, multi-level and various measures combining the application of innovative talents cultivation model, which require graduate students to participate in national innovation projects and innovation platform construction and other competitions through implementing the postgraduate comprehensive system and reforming the traditional way of teaching and practice[5-7].

\section{THE WAY OF IMPROVING THE INNOVATIVE ABILITY}

A. Reforming the teaching system and exploring the knowledge system to adapt to the cultivation of innovative ability.

Graduate course has a strong selective systemic, flexibility and self. To promote their knowledge structure is reasonable and perfect, develop intelligence and ability, their study is in the process of accepting and grasping knowledge. John Pass said that the purpose of postgraduate education is to develop graduate student scientific research ability, prompting them to some important and fundamental problems in criticism and judgment. Strengthening the cultivation of postgraduates' scientific research ability is the essential and inherent requirement of postgraduate education. Therefore, it is necessary to make graduate students master the discipline of a solid basic theory and system of scientific knowledge, but also enable them to engage in scientific research work and undertake specialized technical work independently. In the case of three-year academic, master's degree must spend 1 year to study course and 2 years to carry out the dissertation research and write topics. At this time, in order to award degrees, graduate degrees are usually based on the degree thesis to measure their scientific research ability, required to publish public journal articles before the defense.

1) Reforming the teaching contents and optimize cultivation system.

The optimization of curriculum system including:

(1) The core curriculum must be strengthened, which should absorb the latest achievements of this discipline for graduate students to lay the solid basic knowledge.

(2) The proportion of the compulsory and elective courses must be set in a reasonable way. Increasing the proportion of elective courses is beneficial to construct the individualized curriculum system for postgraduates. Simultaneously, interdisciplinary and comprehensive courses can be 
appropriated to expand the knowledge, enrich the personality and creativity of postgraduates.

(3) Studying political theory is aimed at strengthen professional ethics; cultivate the spirit of unity and the scientific quality of upholding truth. Learning foreign languages is to cultivate graduate students' ability of using language comprehensively and conducting international academic exchanges. With the shortening of academic structure and the adjustment of training objectives, it is necessary to optimize the setting of public basic courses, as for how to optimize need for further study.

(4) Paying attention to the dynamics of curriculum system and building a flexible curriculum structure are easy to make changes along with the social demand and cultivate talents in line with social development need. The flexible curriculum structure provides more selective and space of personalized development for the graduate student.

The existing environmental engineering professional talent training target remains some deficiency. Through research, it is proposed to use the "three levels" knowledge system, which is professional basic knowledge, comprehensive ability and innovation ability cultivation. Basic knowledge cultivation mainly services for foundation course, such as general chemistry, analytical chemistry, physics, etc. Comprehensive ability cultivation is as the core of environmental engineering professional course, such as water treatment and pollution control process, etc. Innovation ability cultivation mainly develop innovative theory and practice teaching in the area of waste water and solid treatment and recycling, need assimilate advanced technological achievements and modern education technology into the teaching process, which makes the optimized teaching content and structure more scientific, systemic and practical.

2) Classifying the talent cultivation and reforming the training system.

With the development of economy and the change of social demand for talent, the postgraduate orientation has changed; universities must change the concept of talent. According to the different requirement of different industry and different position for the talent, it would enrich the postgraduate training objectives and specifications, reform the training plan and curriculum system, establish the classifying cultivation mechanism of academic talents and applied talents, and build a diversified high-level talent training system. For academic talents, it is important to optimize the training process and improve the quality and efficiency of training. For applied talents, according to the requirements of the market and the industry in technology, we should combine application and flexibility in the training plan and curriculum setting, and actively explore talent training mode of the school-enterprise cooperation education.

3) Strengthen postgraduate cooperation in production, studying and research inside and outside school.

We should actively explore new ways of using social resources to carry on the graduate cultivation, work with scientific research units, local enterprises to seek cooperation, and use the actual scientific research and engineering projects to guide graduate students' innovation activities and postgraduate research practice, while strengthening the school laboratory and research room construction. By the way of building scientific research and practice base with research institutes, enterprises and institutions, which can make student to go deep into the first line of research and production, get exercise from all aspects of theoretical knowledge, technological process, production technology and management, combine theoretical knowledge with production practice. It plays an irreplaceable role in teaching. Postgraduate training requires flexibility and diversification, it can make postgraduate to combine with their interests and strengths and give full play to their theoretical innovation or practical problem-solving ability from the characteristics of the discipline.

The formation of innovative thinking in the teaching process is mainly reflected in the brain. Neurophysiology studies have shown that the number of neurons in the human brain can reach about $10,000,000,000$, but actually use only 20 $30 \%$, the remaining neurons are not developed and utilized. Therefore, we should explore the suitable and effective teaching system to adapt to the cultivation of innovative talents, develop the brain of the graduate student to promote the whole brain to learn, fully stimulate the enthusiasm and creativity of graduate students and learning happily.

\section{B. Optimizing the innovation and practice environment and exploring the cultivation methods of postgraduates' scientific research ability.}

With the development of economy and society, the demand for talents in the market has changed, which requires not only theoretical talents, but also a large number of applied and compound talents. The applied and compound talents training goal is mainly to cultivate the ability to solve practical problems, so the cultivation of practice ability will be more and more important in the present and future graduate education. And scientific research ability is the core of practice ability, which is formed from the process of using existing knowledge and scientific methods to explore new knowledge and problems. The cultivation of the scientific research ability is the highest requirement and the most important content of graduate education. The best measure of their level and quality is the depth of research training and the results achieved. Therefore, the graduate education should get rid of the shackles of traditional teaching ideas and transfer from the emphasis on knowledge base to the development of scientific research ability. The research ability of graduate students mainly includes the scientific judgment ability, choosing goals and topics ability, analytical thinking ability, independent research ability and application transformation ability.

1) Advancing scientific research and cultivating the spirit of innovation.

The instructor research project is not only a bridge between the school and society, but also the link of training the students to use the knowledge to solve practical problems. By combining theory with practice, graduate students complete the instructor research projects, which can not only enhance the practical ability and the understanding and consolidation of theoretical knowledge, but also increase the access to all kinds 
of information, active graduate students thinking and sparking innovation spark. For further study students, active participation in research is particularly important.

(1) The research can effectively cultivate the ability of graduate students to engage in scientific research independently. At the same time, graduate students can continue to receive guidance and feedback, effectively improve the comprehensive use of knowledge and skills, and training of thinking ability.

(2) If the graduate student participate in the approved project research, which can strengthen the graduate student's ability to judge and grasp the social problems. If the graduate student participate in the optional subject research, which can increase the graduate student to achieve the newest trend of the research and exercise their ability to search problem in the process of finding problem.

(3) The research can enhance the graduate student's selfmanagement ability and communication ability. For example, it is inevitable that the graduate student participation in the project requires cooperation and communication with others. However, how to arrange the time and complete the task on time for the training of students' time management and selfcontrol is very effective.

2) Selecting the appropriate research projects and enhancing the ability of innovation and practice.

In practice, it is attention to link with the creative ability and the personality development. The curiosity and personality of the graduate students should be encouraged in the scientific research experiment. At the same time, graduate students should choose reasonable scientific research projects. If the personality can get healthy development, the potential of creativity can also be fully played. The research project is absolute irreplaceable to cultivate graduate student's practical ability and innovation ability. By taking the graduate student as the main body to complete the actual scientific research project, it is a great promotion to the comprehensive ability and innovation ability of graduate students. For example, making the National Graduate Challenge Cup and other scientific and technological competition as the entry point, it can face to face communicate with graduate students for the existing problems, research ideas and improving views in their works, give them practical guidance, and help them improving the ability of technological innovation. By 2-3 graduate research practice, the practical innovation ability of graduate students can be cultivated from shallow too deep to find problem, analyze the problem and solve the problem.

3) Implementing the graduate tutor responsibility system and improving the comprehensive ability of innovation.

The graduate tutor responsibility system is to make the graduate student to get scientific training as early as possible, cultivate and improve the innovative spirit and practical innovation ability and improve the comprehensive quality. Letting the innovation consciousness of the graduate student to carry on and experience the fun from innovation, which can stimulate their more enthusiasm. Graduate students can be in a high state of innovation for a long time, which will germinate their desire to study and a variety of potential, as long as the situation, the overall strength of the graduate students will be more prominent by the desire of learning. Therefore, it is necessary to put graduate student development first, train both ability and integrity and focus on moral, intellectual, physical and aesthetic development. On one hand, we should pay attention to the physical education of graduate students so that they have a healthy body for protection to intellectual and moral education. On the other hand, we should also pay attention to the aesthetic education, cultivate students' ability to discover, experience and appreciate beauty, which may promote them to purify the mind and cultivate sentiments. Aesthetic education plays a very important role in maintaining physical and mental health, shaping healthy personality and improving the ability of innovation.

\section{Improving the teaching environment and exploring the teaching method of practical and innovative talents training.}

Teachers should consciously innovation the teaching content and method and add applied stronger course according to the training goal. Most of the courses should not be taught in the form of indoctrination, but should be based on the characteristics of the curriculum, extensive and flexible use of case-based teaching, discussion of teaching, lecture-style teaching, debate teaching, research teaching, academic salon, academic reports and lectures and other teaching methods. At the same time teachers should not cultivate applied talents in the way of cultivating academic talents. As studying for an applied degree, the training aim should focus on high level applied talents of solving practical problems, be based on improving their practical ability and skill. Therefore, teachers should be more contact with social reality and focus on cultivating graduate students to find, analyze and solve practical problems, which don't need as high standard requirement as academic postgraduate students.

As the center of the professional courses teaching in the teaching process, we should allow the graduate students to take the initiative to learn with the problem so that they can understand, master and apply professional knowledge.

1) We should create the teaching environment of active participation, let graduate students master the initiative to learn, set their own learning goal and plan to complete the professional course study.

In order to cultivate students' self-exploration ability, teachers should guide the graduate students to find and analyze problems in the rich information resources and instructor research project, form a solution to the specific problems. For example, teachers can consciously leave a blank in the course of teaching. That is to say, teachers leave some teaching time and content for the graduate students to speculate on possible conclusions. The purpose is to improve the creativity of graduate students and promote them to participate in the teaching process actively. Of course, in the process of learning, teachers' moderate help is necessary, but mainly assist and guide, which make graduate students to complete their own learning to the initial innovation. 
2) We should create a knowledge and experience sharing environment, so that graduate student can learn in the practice cooperation.

Teachers should create a good cooperative learning atmosphere and create more real problems and cases or design and put forward some enlightening problems, interact with students to think, discuss and communicate, which will lead graduate students to enter the actual situation through experiments, imitation, inspection, investigation and so on. At this time, whether playing a role or not, the graduate students will go to experience and feel, develop thinking and grow the ability of solving the problem in the immersive. The study way of the final solution to the actual problem and cooperative completion, will make students thinking more active and be more beneficial to stimulate their enthusiasm to make progress. That will create conditions and useful experience for graduate students to create practical innovative learning.

Graduate education is both science and art. In the teaching practice of graduate students, flexible and diverse teaching methods, relaxed and harmonious teaching environment, which is conducive to exert the initiative of graduate students in learning activities and develop their innovative thinking so that the graduate study would becoming more and more diverse.

\section{CONCLUSIONS AND SUGGeSTIONS}

In short, the ministry of education issued 'Several Ideas to Strengthen and Improve the Work of Graduate Student Training'; file explicitly pointed out that we should promote quality education and highlight the cultivation of innovation ability, practical ability and Entrepreneurial Spirit. Innovation is the survival and development road of scientific research, is also the soul of scientific research. But many people are still limited to the view of innovation in the update, change and create new things. In fact, we should open up the concept of innovation. In the cultivation of graduate students' scientific research ability, we should help them to learn how to find problem in practical activities, which makes the process of finding problem become a questing, thinking and verifying process. It doesn't matter that the theoretical basis and research method they choose is not applicable, however the graduate student's innovation consciousness and the innovation ability will be promoted in this process.

\section{ACKNOWLEDGMENT}

The authors gratefully acknowledge the financial support from the Graduate Education Teaching Reform Project of WUST(Yjg201530).

\section{REFERENCES}

[1] Ujang, Z., Henze, M., Curtis, T., Schertenieib, R. and Beal, L.L., Environmental engineering education for developing countries: framework for the future. Water Sci. and Tech., Vol.49 (2004), p.1-10

[2] Alha, K., Holliger, C., Larsen, B.S., Purcell, P. and Rauch, W., Environmental engineering education - summary report of the 1st European Seminar. Water Sci. and Tech., Vol. 41(2000), p.1-7

[3] Cao Jie, Zhang Xiaoling, Wu Wu, Thinking and Exploration on the mode of postgraduate education and training of professional degree master, Tsinghua Journal of Education, Vol. 36(2015), p. 60-63(In Chinese)

[4] Chang Xin Hua, Qi Yadong, Zhang Zhiqiang, Wang Lanzhen, He Yiling, Jiang Tao, Comparative study on the mode of graduate education between China and America, Higher agricultural education, Vol. 8(2014), p. 119-124(In Chinese)

[5] Sun Youlian, On the construction of the new graduate education model, Development and evaluation of Higher Education, Vol. 30(2014), p. 6474(In Chinese)

[6] Chen Xing, Liu Yi, Comprehensive quality training of master students in large data environment, Weekly journal, Vol. 36(2016), p. 17-18(In Chinese)

[7] Ma Jing, Zhao Guirong, Wang Quanjiu, Exploration and Reflection on the training mode of full-time Master Degree Postgraduates, Chinese and foreign educational research: Youth Society, Vol. 4(2010), p. 4143(In Chinese) 